\title{
Clinical manifestations of allergy related to breast and cows' milk feeding
}

\author{
DAVID W HIDE AND BARRY M GUYER \\ St Mary's Hospital, Newport, Isle of Wight, and Mead Johnson, Langley, Berkshire
}

SUMmaRY The frequency of allergic manifestations in the first year of life was studied. The prevalence of allergic signs affecting the skin and respiratory tract in infants who had been started on breast feeding was compared with the prevalence of such signs in infants started on cows' milk formulae. The relationship of allergy to family history was investigated. Eczema and rhinitis were found to be present as often in the initially breast-fed group as in the initially cows' milk-fed group. Bottle-fed infants developed asthma and bronchitis more often than their breast-fed counterparts. Infants of allergic parents exhibited more allergy than those from non-allergic families, and this difference was particularly pronounced for asthma or bronchitis. Breast feeding gave some protection against the development of respiratory tract allergies in infants of non-allergic parents. Among the infants with a positive family history of allergy, fewer with eczema or chronic rhinitis were found in the initially breast-fed group but this did not achieve statistical significance.

Breast feeding is widely believed to protect the newborn infant against the development of allergic disease. Certainly many authorities have found a greater prevalence of allergic disorders in infants fed on cows' milk compared with infants fed on soya bean milk or breast milk. Glaser and Johnstone ${ }^{1}$ found that $15 \%$ of children from allergic families fed soya milk from birth to age 6 months had developed allergic disease by age 6 years. $65 \%$ of sibling controls and $52 \%$ of unrelated controls fed cows' milk formulae developed allergies. Subsequently, Johnstone and Dutton ${ }^{2}$ confirmed these findings in a prospective study of $\mathbf{2 3 5}$ children from allergic parents who were followed up for 10 years. However, Halpern et al., ${ }^{3}$ in a study of 1753 infants fed breast, soya, or cows' milk from birth to 6 months, concluded that the presence of allergic disease was not affected by diet, except for the fact that babies fed cows' milk tended to show their allergy earlier than those who had been breast fed.

All studies have shown that a positive family history of allergy predisposes the infant to develop allergic disease. Recently it was claimed that exclusive breast feeding could reduce the incidence of atopic eczema in predisposed infants. Matthew et al. ${ }^{4}$ found that only 2 of 23 infants who had received breast milk in the first 6 months of life had developed eczema by this age; a third child had developed eczema by the time he was 1-year old. Efforts were also made to protect the infants from other aller- gens-such as pets, feathers, or house dust mites. A second group of infants was fed on cows' milk and not subjected to such antigen avoidance. Nine of the 19 had developed eczema by 6 months and there was a similar prevalence at 1 year. In all cases at least one parent had a history of asthma, allergic rhinitis, or eczema. These results were greeted by the Lancet $^{5}$ as being of great practical importance in the prevention of allergy. However it was noted that skin tests did not show a significant difference between the regimen and non-regimen groups. Saarinen et al. ${ }^{6}$ in Finland concluded that prolonged breast feeding led to a lower incidence of severe or obvious atopic disease, particularly in infants with a family history of atopy.

In April 1977, a prospective study of all infants born on the Isle of Wight during a 12-month period was started. The objectives were to determine the incidence of feeding problems and allergic disease in an entire infant population and to relate such incidence to the mode of feeding and to parental history of allergic disease.

\section{Methods}

Complete data were collected on 843 infants born on the Isle of Wight between 1 April 1977 and 31 March 1978. The family history of allergic disease was obtained from each mother before delivery. Health visitors visited the mother and 
Table 1 Parental history of atopy

\begin{tabular}{lcc}
\hline & Percentage \\
\cline { 2 - 3 } & $\begin{array}{l}\text { Of fathers } \\
(n=843)\end{array}$ & $\begin{array}{l}\text { Of mothers } \\
(n=843)\end{array}$ \\
\hline & & $19 \cdot 0$ \\
Overall incidence & $15 \cdot 9$ & $4 \cdot 7$ \\
Eczema & $2 \cdot 3$ & $10 \cdot 8$ \\
Hay fever & $10 \cdot 8$ & 8.4 \\
Asthma & 7.0 & P. \\
\hline
\end{tabular}

Table 2 Incidence of allergy in infants who were started on breast feeding compared with those who were started on cows' milk formulae

\begin{tabular}{|c|c|c|}
\hline & $\begin{array}{l}\text { Breast feeding } \\
\text { initiated }(n=596)\end{array}$ & \multirow{2}{*}{$\begin{array}{l}\begin{array}{l}\text { Bottle feeding } \\
\text { initiated }(n-247)\end{array} \\
N o(\%)\end{array}$} \\
\hline & No $\%$ & \\
\hline Eczema & $47(7 \cdot 9)$ & $22(8 \cdot 9)$ \\
\hline Chronic rhinitis & $135(22 \cdot 7)$ & $65(26 \cdot 3)$ \\
\hline Asthma or bronchitis & $44(7 \cdot 4)$ & $29(11 \cdot 7)$ \\
\hline Overall incidence allergy & $224(37 \cdot 6)$ & $114(46 \cdot 2)$ \\
\hline
\end{tabular}

Two infants in each group had double allergies.

The difference in overall incidence of allergy is statistically significant $\left(\chi^{2}=4 \cdot 989, \mathrm{P}<0.05\right)$.

Table 3 Incidence of allergy in infants and effects of parental allergy

\begin{tabular}{lcl}
\hline & $\begin{array}{l}\text { Parental history } \\
\text { of allergy } \\
(n=266)\end{array}$ & $\begin{array}{l}\text { No parental history } \\
\text { of allergy } \\
(n=577)\end{array}$ \\
\cline { 2 - 3 } & No $(\%)$ \\
\hline Eczema & $28(10 \cdot 5)$ & $41(7 \cdot 1)$ \\
Chronic rhinitis & $67(25 \cdot 2)$ & $133(23 \cdot 1)$ \\
Asthma or bronchitis & $31(11 \cdot 7)$ & $42(7 \cdot 3)$ \\
Overall incidence allergy & $125(47 \cdot 0)$ & $213(36 \cdot 9)$ \\
\hline
\end{tabular}

One infant in the history of parental allergy group and 3 in the nonallergic group had double allergies.

The difference in the incidence of asthma or bronchitis in the two groups is statistically significant $\left(\chi^{2}=3 \cdot 870, \mathrm{P}<0 \cdot 05\right)$.

The difference in overall incidence of allergy is statistically significant $\left(\chi^{2}=7 \cdot 284, P<0.01\right)$. questionnaires were completed at $6,12,26$, and 52 weeks after birth. Most of the mothers kept a diary in which was recorded anything the mother thought might be related to the infant's diet. Preliminary results were reported by Hide and Guyer. ${ }^{7}$ This paper records the results of the study after one year of follow-up.

\section{Results}

Table 1 shows the history of allergic disorders as given by the parents. A total of 134 fathers and 160 mothers had at some time suffered from eczema, asthma, or hay fever. Parents who gave a less clear history of allergy-for example food allergy, urticaria, or contact sensitivity-were not included in the allergic group. A total of 266 infants had at least one parent with at least one atopic symptom. Such infants were compared with 577 others whose parents had no such history.

Table 2 shows the incidence of infant allergy with respect to method of initial feeding, regardless of any subsequent change in feeding pattern. The reasons for this method of analysis are given later. In Table 3 the incidence of allergic manifestations in infants whose parents gave an allergic history is compared with those who had no recorded allergy. Table 4 gives an analysis of infant allergy with respect to parental history and method of initial feeding. The relative incidence of infant allergy with respect to the final method of feeding is shown (Table 5).

Definitions. In these tables the following definitions were used:

The diagnosis of eczema was in each case made by a doctor, generally the GP. It was felt that many family doctors are reluctant to diagnose eczema; it is an emotive word and produces considerable

Table 4 Incidence of infant allergy according to parental history and initial method of feeding

\begin{tabular}{|c|c|c|c|c|}
\hline & \multicolumn{2}{|c|}{ Parental history of allergy $(n=266)$} & \multicolumn{2}{|c|}{ No parental history of allergy $(n=577)$} \\
\hline & $\begin{array}{l}\text { Breast feeding } \\
(n=204)\end{array}$ & $\begin{array}{l}\text { Bottle feeding } \\
(n=62)\end{array}$ & $\begin{array}{l}\text { Breast feeding } \\
(n=392)\end{array}$ & $\begin{array}{l}\text { Bottle feeding } \\
(n=185)\end{array}$ \\
\hline & No $(\%)$ & $N o(\%)$ & No $(\%)$ & No $(\%)$ \\
\hline $\begin{array}{l}\text { Eczema } \\
\text { Chronic rhinitis } \\
\text { Asthma or bronchitis } \\
\text { Overall incidence allergy }\end{array}$ & $\begin{array}{l}20(9 \cdot 8) \\
48(23 \cdot 5) \\
24(11 \cdot 8) \\
92(45 \cdot 1)\end{array}$ & $\begin{array}{r}8(12 \cdot 9) \\
19(30 \cdot 6) \\
7(11 \cdot 3) \\
33(53 \cdot 2)\end{array}$ & $\begin{array}{r}27(6 \cdot 9) \\
87(22 \cdot 2) \\
20(5 \cdot 1) \\
132(33 \cdot 7)\end{array}$ & $\begin{array}{l}14(7 \cdot 6) \\
46(24 \cdot 9) \\
22(11 \cdot 9) \\
81(43 \cdot 8)\end{array}$ \\
\hline
\end{tabular}

In the allergic group one bottle-fed infant had a double allergy.

In the non-allergic group 2 breast-fed and one bottle-fed infant had double allergies.

Within the non-allergic group, the difference in incidence of asthma/bronchitis is statistically significant $\left(\chi^{2}=7 \cdot 609, \mathbf{P}<0 \cdot 01\right)$.

Within the non-allergic group, the difference in overall incidence of allergy is statistically significant $\left(\chi^{2}=5 \cdot 091, P<0.05\right)$

Between the breast feeding groups, the difference in incidence of asthma/bronchitis is statistically significant $\left(\chi^{2}=7 \cdot 764, P<0 \cdot 01\right)$.

Between the breast feeding groups, the difference in overall incidence of allergy is statistically significant $\left(\chi^{2}=6 \cdot 986, P<0 \cdot 01\right)$. 
Table 5 Incidence of infant allergy according to final feeding method

\begin{tabular}{|c|c|c|c|c|}
\hline & $\begin{array}{l}\text { Only breast fed } \\
(n=155)\end{array}$ & $\begin{array}{l}\text { Mixed breast/bottle } \\
(n=441)\end{array}$ & $\begin{array}{l}\text { Only bottle fed } \\
(n=83)\end{array}$ & $\begin{array}{l}\text { Bottle and cereals/solids } \\
(n=164)\end{array}$ \\
\hline & $N o(\%)$ & $N o(\%)$ & $N o(\%)$ & $N o(\%)$ \\
\hline $\begin{array}{l}\text { Eczema } \\
\text { Chronic rhinitis } \\
\text { Asthma or bronchitis } \\
\text { Overall incidence allergy }\end{array}$ & $\begin{array}{r}13(8 \cdot 4) \\
28(18 \cdot 1) \\
6(3 \cdot 9) \\
47(30 \cdot 3)\end{array}$ & $\begin{array}{r}34(7 \cdot 7) \\
107(24 \cdot 3) \\
38(8 \cdot 6) \\
177(40 \cdot 1)\end{array}$ & $\begin{array}{r}11(13 \cdot 3) \\
21(25 \cdot 3) \\
7(8 \cdot 4) \\
38(45 \cdot 8)\end{array}$ & $\begin{array}{l}11(6 \cdot 7) \\
44(26 \cdot 8) \\
22(13 \cdot 4) \\
76(46 \cdot 3)\end{array}$ \\
\hline
\end{tabular}

parental anxiety. Thus we do not consider that the condition was over-diagnosed in this study.

'Chronic rhinitis' was recorded for infants stated to have persistent upper airways obstruction or snuffles. Any child who had had at least one episode of lower respiratory tract obstructive disease was recorded in the 'asthma or bronchitis' group.

'Breast feeding initiated' and 'bottle feeding initiated' were the terms used by the parents to describe the initial method of feeding. In this series $71 \%$ of the infants were breast fed initially. The terms 'only breast fed' and 'only bottle fed' were used to describe infants fed only by breast or bottle for a period of at least 6 months without the introduction of cereals or solids before age 3 months. 'Mixed breast/bottle' was the term used to describe the group of infants initially started on the breast but who subsequently were either wholly transferred to bottle feeding before age 6 months or had cereals (almost certainly admixed with cows' milk) or solids introduced in the first 3 months of life. 'Bottle and cereals/solids' was the term used to describe the infants who were begun on cows' milk formulae and had cereals or solids introduced by age 3 months.

The overall incidence of allergic signs was greater in infants started on formulae feeds than in those started on the breast (Table 2), though the differences in the individual groups did not reach statistical significance. Similarly (Table 3 ), infants of allergic parents demonstrated more allergy themselves, and in this instance the difference in the rates for asthma or bronchitis attained significance as well.

The highest incidence (53\%) of allergic manifestations occurred in the bottle-fed infants of allergic parents, and the lowest incidence (34\%) was found in the breast-fed babies of non-allergic parents (Table 4). Breast feeding was seen to be beneficial to infants in the non-allergic group, particularly to those vulnerable to asthma or bronchitis.

\section{Discussion}

This study supports the opinion of Halpern et al. ${ }^{3}$ that a negative family history seems the best assurance against acquiring an allergic disease; our overall incidence of allergic manifestations in the negative history group was lower than that in infants of allergic parents.

It was shown too that breast feeding apparently reduces the overall allergic incidence. This is most clearly seen in the protection gained against asthma or bronchitis by breast-feeding infants in whom there is no family history of allergy.

Table 5 sets out the incidence of allergy in the various infant groups according to final method of feeding. We feel that although these results are interesting, caution should be exercised in interpreting the findings as they represent groups of selfselecting subjects. For example, the incidence of allergy in the only breast-fed group is substantially lower than that found in the other groups; this is not surprising as any infant initially breast fed who develops problems (whether related to feeding, allergy, or any other cause) is likely to have had his method of feeding changed. Similarly, an infant not thriving on cows' milk alone may have cereals or solids introduced to his diet.

We chose to present the data in a form that reflected practice in life-namely that an initial decision on the method of feeding is made and that this is or is not continued throughout early infancy. Notwithstanding the considerable drop-out rate from the breast feeding group $(71 \%$ initially purely breast fed, only $18 \%$ continuing to 6 months), advantages for initiating breast feeding - even if it becomes impractical or impossible to maintainhave been demonstrated.

This study failed to give absolute evidence that breast feeding protects against the development of eczema. It may be that when these children are studied further into childhood a significantly lower prevalence of eczema will be found in those initially breast fed. Mothers who breast-fed their infants were not given advice on a strict allergen avoidance regimen, nor were they subjected to carefully controlled weaning (for example, avoiding dairy products, fish, and eggs) unlike the infants studied by Matthew et al. ${ }^{4}$ It has been suggested that as breast feeding is currently more often practised by women 
in the higher social classes who may well have better access to medical advice, there might be an over-diagnosis of such disorders as eczema in the breast-fed group. The study of our data did not show any significant difference in the prevalence of allergic disorders either in the parents or the infants when analysed in accordance with father's social class. We are aware that our data record a higher incidence of allergic manifestations than had previously been recorded. We consider that the reported rate of eczema is an accurate reflection of the incidence in the first year of life. Persistent upper airways obstruction (chronic rhinitis) may not always be an allergic manifestation although we think that allergy is often the basis for this sign. Asthma or bronchitis, as defined in this study, may not necessarily mean that the infant is atopic but the association between wheezing episodes in infancy and the subsequent diagnosis of asthma is close and is the best clinical sign available to us.

The greater prevalence of overall allergy in infants who were initially bottle fed persuades us that breast milk is preferable for babies, regardless of parental allergic status. The predisposition to asthma or bronchitis of cows' milk-fed infants of non-allergic parents (which would appear to be preventable by initiating breast feeding) suggests to us that the family history with respect to allergy should be investigated in the antenatal clinic, so that the advantages of breast feeding to infants not compromised by a positive history may be explained.

The study has been an attempt to define clinical signs of allergy in an entire infant population. The validity of these observations will be clarified as the study continues.
We thank Miss Barbara Jones and Mrs Jean Bedford for taking the allergy histories, all the Health Visitors of the Isle of Wight Health Authority for their considerable efforts in completing the follow-up questionnaires, and Mrs Doreen Bacon who acted as Secretary to the study and collated much of the information.

\section{References}

1 Glaser J, Johnstone D E. Prophylaxis of allergic disease in the newborn. JAMA 1953; 153: 620-2.

2 Johnstone D E, Dutton A M. Dietary prophylaxis of allergic disease in children. $N$ Engl J Med 1966; 274: 715-9.

3 Halpern S R, Sellars W A, Johnson R B, Anderson D W, Saperstein S, Reisch J S. Development of childhood allergy in infants fed breast, soy, or cows' milk. J Allergy Clin Immunol 1973; 51 : 139-51.

4 Matthew D J, Taylor B, Norman A P, Turner M W, Soothill J F. Prevention of eczema. Lancet 1977; i: 321-4.

5 Anonymous. Towards prevention of allergy. Lancet 1977; i: 339 .

6 Saarinen U M, Backman A, Kajosaari M, Siims M A. Prolonged breast feeding as prophylaxis for atopic disease. Lancet 1979; ii: 163-6.

7 Hide D W, Guyer B M. Isle of Wight infant feeding survey. In: Pepys J, Edwards A M, eds. The mast cell: its role in health and disease. Tunbridge Wells: Pitman Medical, 1979: 844.

Correspondence to Dr D W Hide, St Mary's Hospital, Paediatric Department, Newport, Isle of Wight PO30 5TG.

Received 5 December 1979 